University of Nebraska - Lincoln

DigitalCommons@University of Nebraska - Lincoln

April 1994

\title{
Almost Ideal Area Yield Crop Insurance Contracts
}

Vincent H. Smith

Montana State University

Hayley H. Chouinard

Montana State University

Alan E. Baquet

University of Nebraska-Lincoln, abaquet1@unl.edu

Follow this and additional works at: https://digitalcommons.unl.edu/ageconfacpub

Part of the Agricultural and Resource Economics Commons

Smith, Vincent H.; Chouinard, Hayley H.; and Baquet, Alan E., "Almost Ideal Area Yield Crop Insurance Contracts" (1994). Faculty Publications: Agricultural Economics. 63.

https://digitalcommons.unl.edu/ageconfacpub/63

This Article is brought to you for free and open access by the Agricultural Economics Department at DigitalCommons@University of Nebraska - Lincoln. It has been accepted for inclusion in Faculty Publications: Agricultural Economics by an authorized administrator of DigitalCommons@University of Nebraska - Lincoln. 


\title{
Almost Ideal Area Yield Crop Insurance Contracts
}

\author{
Vincent H. Smith, Hayley H. Chouinard, and Alan E. Baquet
}

\begin{abstract}
Using yield data for a sample of 123 dryland wheat producers in Montana, the effects of three area yield contracts, including the contract currently offered by the United States Federal Crop Insurance Corporation and two individual yield contracts on individual farm yield variability, are examined. The results indicate that while the Federal Crop Insurance Corporation area yield contract provides all farmers in the sample with some protection against yield variability, a simpler, actuarially equivalent "almost ideal"' area yield contract provides substantially larger reductions in yield variability. However, actuarially equivalent individual yield contracts provide levels of protection against yield variability similar to those obtained under the "almost ideal" area yield contract at much lower premiums.
\end{abstract}

The debate over farm programs that preceded passage of the 1990 United States Food, Agricultural, Conservation and Trade Act (the 1990 Farm Bill) took place in the context of a government wide drive to reduce the federal budget deficit. During the course of that debate, serious attention was given by both the House and Senate agricultural committees to the costs of the federal crop insurance program, which was variously estimated to have cost the federal government between $\$ 700$ million and $\$ 800$ million per year in subsidies for administrative expenses and the payment of indemnities for losses. The subsidies in and of themselves constituted a problem for the program. The fact that ad hoc disaster relief bills had commonly been passed to deal with damage to crops and livestock from "Acts of God" during the 1980s also called into question the validity of the program. Under the 1980 Federal Crop Insurance Act, the program had been deliberately expanded with respect to the range of crops covered and the geographic regions in which insurance would be available to obviate the need for ad hoc disaster relief to the farm sector. Most farmers, however, chose not to participate in the program (participation rates averaged just over 20 percent during that period) and, instead, elected either to use other methods for managing income risk or to rely on the political system to provide free (to the farmer) protection through ad hoc disaster relief bills.

\footnotetext{
The authors, respectively, are Assistant Professor, Research Associate, and Associate Professor, Department of Agricultural Economics and Economics, Montana State University. The authors gratefully acknow1-
} edge the valuable comments of three anonymous reviewers.
In fact, the Congressional House and Senate agricultural committees and the administration decided not to change the existing federal crop insurance program in the 1990 farm bill but did agree to review the program in subsequent Congressional sessions and to allow the FCIC to test new products on a pilot basis. Budgetary pressures did not ease during the early 1990 s and major innovations in the structure of the federal crop insurance program are now being examined by the Federal Crop Insurance Corporation (FCIC), which administers the federal crop insurance program, in response to initiatives from both the Clinton Administration and the Congress. In particular, the FCIC is introducing a national area yield crop insurance program-called the Group Risk Plan (GRP)-and, for the 1993-94 crop year, is offering area yield contracts in over 100 wheat or soybean producing counties on a pilot project basis.

Area yield insurance contracts (first proposed by Halcrow in 1949) provide the purchasing farmer with an indemnity only when average yields across all farms in the area fall below a critical yield. Typically, it is assumed, the individual farm's yield will have only a small impact on area yield and therefore area yield crop insurance contracts do not provide such large incentives for moral hazard or adverse selection. As Miranda has argued, area yield insurance does provide farmers whose individual yields are closely correlated with area yields with considerable protection against yield and, therefore, income variation. The exact form of the area yield contract may have a substantial impact on the amount by which the variance of a farm's yields and income can be reduced. 
This paper examines the effects of alternative area yield contracts on the variance of farm output and income net of insurance premiums. We show for a sample of 123 dry land wheat producing farms from the same county in Montana that the current area yield contract being offered is suboptimal. A simpler and more flexible area yield contract would permit the average farmer in the sample to reduce the variance of its yields by about 20 percent more than the current GRP contract.

\section{Alternative Multiple Peril and Area Yield Crop Insurance Programs}

From its inception in 1938 until 1993, the FCIC provided insurance coverage to the individual farm against individual farm losses from multiple perils. ${ }^{1}$ Under a typical multiple peril crop insurance (MPCI) contract the farm incurs a loss when its actual yield falls below a predetermined percentage, $a_{i}$, of its average yield, $\mu_{i}{ }^{2}$ Historically, the farm has been able to choose one of three yield election values for $a_{i} ; 0.5,0.65$ or 0.75 . Contracts with 50 percent and 65 percent yield elections have been more heavily subsidized than contracts with 75 percent yield elections. In the event of a loss, the indemnity paid to the farm is the difference between this critical yield, $y_{c i}=a_{i} \mu_{\mathrm{i}}$, and the actual yield, multiplied by the price election selected by the farm. Gardner and Kramer have pointed out that over the history of the program from 1938-83, except for periods in which MPCI was offered only on a very limited basis, indemnities or losses paid out by the program have typically exceeded the premiums paid into the program resulting in loss ratios (the ratio of indemnities to premiums) well in excess of one. In the 1980s, as Miranda has reported, the average loss ratio for the entire MPCI program increased to just over two. ${ }^{3}$

Most economic analyses of the current MPCI program attribute the high loss ratios observed throughout most of the program's history to problems of adverse selection and moral hazard. In the

\footnotetext{
1 Under a multiple peril contract the farmer is protected from all crop losses other than those caused by poor farming practices.

${ }^{2}$ For crop insurance purposes, the farm's average yield is determined by FCIC to be its ten year actual production history (APH) or, if a complete ten year history is not available, by a combination of its actual available production history and proxies such as its ASCS yield. Skees and Reed have argued that this approach to yield determination may result in adverse selection because of upward drift in yields over time because of technical innovation.

${ }^{3}$ The 1980 s included two of the three most severe drought years since 1910 in the corn belt and the Great Plains. Thus, any crop insurance program would probably have experienced loss ratios in excess of one.
}

context of crop insurance, adverse selection occurs when, among the pool of insurable farms, those farms with higher probabilities of loss (and therefore positive expected returns from purchasing insurance) are more likely to purchase insurance. Moral hazard occurs when the purchase of insurance causes the farmer to alter production practices to increase the probability of a loss in ways that cannot be monitored by the insurer. ${ }^{4}$ The potential for both problems in the MPCI program has long been recognized (e.g., Chambers; Halcrow; Gardner and Kramer; Miranda; Nelson and Loehman) although only recently have studies provided empirical evidence of adverse selection (Goodwin; Goodwin and Kastens; and Just and Calvin, 1993a) and moral hazard (Coble, et al.; Horowitz and Lichtenberg; Goodwin and Kastens; Just and Calvin, 1993b). In fact, the absence of private insurance programs has been taken as at least partial evidence of the severity of these problems (Gardner and Kramer; Miranda). However, Bardsley et al. have suggested that the benefits of actuarially fair individual crop insurance are small even for farmers with highly variable yields and therefore that there is no mutually beneficial crop insurance contract for both insurer and insuree. ${ }^{5}$

In 1949, Halcrow proposed area yield crop insurance as an alternative to individual yield crop insurance that would resolve problems of adverse selection and moral hazard. His proposal was largely ignored until 1991 when Miranda resurrected the idea and examined the relative effects of area yield and individual yield contracts on the variance of net farm yields and (by implication) gross returns. Miranda examined an area yield contract that had two components, a critical area yield, $y_{c}$, which would trigger indemnity payments, and a coverage level, $\phi$. When area yield, $y$, falls below the critical yield, assuming for simplicity that indemnities are paid in bushels per acre, indemnities received by the farmer, $n$, equal $\phi_{i}\left(y_{c i}-y\right)$; when $y$ exceeds $y_{c i}$ then $\mathrm{n}$ is zero. ${ }^{6}$ Under the contract examined by Miranda the

\footnotetext{
${ }^{4}$ Moral hazard is clearly the result of asymmetric information and therefore often is examined in the framework of the principal agent problem (for examples, see Grossman and Hart; Arnott and Stiglitz; Nelson and Loehman).

${ }^{5}$ Bardsley, et al.'s results suggest that the benefits of rainfall insurance for Australian dry land wheat producers from reductions in income variation are so small that they are less than the administrative costs incurred by private insurers in offering such contracts. Quiggin has disputed Bardsley et al.'s results, and both Fraser and Patrick have reported quite large estimates of willingness-to-pay for multiple peril crop insurance by risk averse farmers.

${ }^{6}$ This involves no loss of generality from an analytical perspective as total premiums are proportional to the price at which a crop is valued under both multiple peril and area yield crop insurance programs.
} 
farm makes only one choice. It selects $\phi_{i}$ but is offered only one critical yield election (that is, $\alpha_{i}$ is determined by the insurer). This contract is quite restrictive. An "ideal" contract would allow the farmer to choose both the critical yield and the coverage level. The farm would choose the critical yield, $y_{c i}=\alpha_{i} \mu$, by selecting the proportion, $\alpha_{i}$, of the long run average or expected area yield, $\mu$, against which to insure and also would select the optimal coverage level. In effect, as Miranda pointed out, area yield contracts offer the farm a hedge against area yield variations through a put option.

Miranda showed that an area yield contract could provide most farms with substantial reduction in net yield variations although Williams et al. and Carriker et al. demonstrated that area yield programs are second order stochastically dominated by actuarially equivalent individual yield insurance contracts. ${ }^{7}$ An interesting feature of the ideal area yield contract is that farmers may select any non-negative values for $\alpha_{i}$ and $\phi_{i}$. Thus a farmer could choose to purchase a contract under which it receives indemnities when actual yields are greater than average yields $\left(\alpha_{i}>1\right)$ and/or receive indemnities that are greater than the difference between the critical area yield and the actual average area yield, $\left(\phi_{i}>1\right) .{ }^{8}$ Contracts in which $\phi_{i}>1$ are optimal area yield contracts for many of the farms in Miranda's example.

If individual yield contracts are associated with irreducible problems of moral hazard and adverse selection then an area yield program, which offers some protection against yield risk to most farmers but vastly reduces incentives for adverse selection and moral hazard, may be a viable alternative to an individual yield program. The FCIC is currently carrying out pilot programs in which GRP area yield contracts are being offered to soybean producers and wheat producers in over 100 selected counties. In addition, in the spring of 1994, similar contracts will be offered in over 1200 counties for barley, corn, cotton, peanuts and grain sorghum.

\footnotetext{
${ }^{7}$ The results presented by Williams, et al. and Carriker, et al. are not surprising. In the early $1960 \mathrm{~s}$, Borch showed that it is always possible to offer an insurance contract in which the purchaser receives a fixed income stream equal to his expected income stream which has no variance. In the absence of problems of adverse selection and moral hazard, such a contract is optimal when the insuree is risk averse and the insurer is risk neutral.

${ }^{8}$ For example, suppose that the expected value of the average area yield, $\mu$, is 30 bushels and that the farm chooses in a contract in which $\alpha_{i}=1.33$ and $\phi_{i}=1.5$. The farm's critical yield is then 40 bushels $y_{c i}$ $=\alpha_{i} \mu$ ). If the actual area yield is 35 bushels then the farm receives an indemnity of 7.5 bushels $\left(\phi_{i}\left[y_{c l}-y\right\}\right)$. The indemnities paid out under such a contract would be much larger than those paid under a contract where both $\alpha$ and $\phi$ were less than one, but the premiums would also be much higher (assuming that both contracts were actuarially fair).
}

The FCIC pilot area yield contract is similar to the ideal area yield contract in that each farmer chooses a trigger yield by picking an $\alpha_{i}$ and, in addition, selects a coverage level, $\phi_{i}$, that also affects its indemnities. One important difference is that under the pilot program the trigger yield can be no greater than 90 percent of the average area yield and the coverage level can be no greater than 150 percent; that is, $\alpha_{i} \leq 0.9$ and $\phi_{i} \leq 1.5$. The FCIC area yield pilot insurance contract is therefore more restrictive than the "ideal" area yield contract and thus is likely to result in smaller reductions in yield and income variances for at least some farms. A second difference is that indemnities are calculated slightly differently. Under the GRP contract, $n_{i}=\operatorname{Max}\left[\phi_{i}\left(y_{c i}-y\right) / \alpha_{i}, 0\right]$. Given that $\alpha_{i}$ is restricted to be less than or equal to 0.9 , this approach results in proportionally larger increases in indemnities as area yields fall. However, note that, as is the case with the ideal contract, $n_{i}>0$ if and only if $y_{c i}>y$.

The FCIC may well have chosen this structure for political reasons. If the farmer picks an $\alpha_{i}$ greater than one indemnities will be received even when actual area yield exceeds its average level. Such an outcome might not look much like individual disaster relief to policy makers. A similar political problem with respect to $\phi_{i}$ is circumvented by FCIC through describing the farmer's choice of $\phi_{i}$ as if it were a choice about the valuation of the crop. ${ }^{9}$ However, if $\phi$ became too large the program might again be criticized for being too generous, even though it might be actuarially fair. Miranda's study of 102 Kentucky soybean producers, however, suggests that such restrictions might considerably reduce the benefits of an area yield program. His results suggest that some producers will enjoy much greater reductions in yield variance if they can pick values $\phi_{i}$ that are greater than 1.

An alternative and simpler approach to the ideal area yield contract is a contract that allows the farm only to choose any trigger yield-that is, to select any value for $\alpha_{i}$-but constrains the value of the coverage level, $\phi_{i}$, to be one. Two questions are relevant with respect to this contract. First, how large is the variance reduction obtained under this type of contract relative to those obtained under the current FCIC pilot contract and under an

\footnotetext{
${ }^{9}$ Under the pilot GRP wheat program for 1993, each bushel of loss is valued at $\$ 2.80$ if $\phi$ equals 1 . If, for example, $\phi$ were set at its maximum value of 1.5 , then each bushel of loss is valued at $\$ 4.20$ but that is, of course, equivalent to inflating the indemnity in terms of bushels by 1.5 . Note that $\$ 4.20$ per bushel is a relatively high price for wheat and in excess of the current target price of $\$ 4.00$.
} 
Table 1. Five Area and Individual Yield Contracts

Area yield contracts

AYC1: The current FCIC pilot area yield contract under which $\alpha_{i} \leq 0.9$ and $\phi_{i} \leq 1.5$.

AYC2: The "almost ideal" contract under which $\alpha_{i}$ may take on any non-negative value but $\phi_{i}=1$.

AYC3: The ideal contract under which both $\alpha_{i}$ and $\phi_{i}$ may take on any non-negative value.

Individual yield contracts

IYC1: The farm is constrained to insure at 75 percent of its average yield $\left(\alpha_{i}=0.75\right)$

IYC2: The farm is constrained to insure at 90 percent of its average yield $\left(\alpha_{i}=0.90\right)$.

ideal area yield contract. Second, how large are the values for $\alpha_{i}$ that are chosen by participating farms.

The three area yield contracts discussed above offer much higher levels of insurance against area yields than have been provided against individual yields under the MPCI program. A fairly common explanation of low MPCI participation rates has been that the maximum trigger yield of 75 percent of average individual yields provides many farms with no protection against yield losses because their yields rarely or never fall below 75 percent of their average yields. ${ }^{10}$ Thus, for purposes of comparison, we also examine the effects on yield variance of two individual yield insurance programs. The first, IYC1, mirrors the current MPCI program by restricting the farm's trigger yield to be 75 percent of its average yield; the second, IYC2, sets the farm's trigger yield at 90 percent of its average yield. The key characteristics of these contractsthe FCIC pilot contract (AYC1), the "almost ideal" contract (AYC2) and the "ideal" contract (AYC3) and the two individual yield contracts (IYC1 and IYC2)-are summarized in $\mathrm{Ta}$ ble 1 .

\section{Theoretical Model}

Following Miranda, consider a farm in an area (county) whose yield is random. The farm's yield, $y_{i}$, can be orthogonally projected onto the area yield, $y$, to obtain the following identity:

$$
y_{i}=\mu_{i}+\beta_{i}(y-\mu)+e_{i},
$$

where,

\footnotetext{
${ }^{10}$ In a sample of 31 California irrigated rice producers examined by Zering et al., very few farms expected to experience actual yields that were less than 75 percent of their average yields.
}

$$
\begin{gathered}
\beta_{i}=\operatorname{Cov}\left(y_{i}, y\right) / \sigma^{2}{ }_{y} \\
E\left(e_{i}\right)=0 ; \operatorname{Var}\left(e_{i}\right)=\sigma^{2}{ }_{e i} ; \operatorname{Cov}\left(y, e_{i}\right)=0, \\
E\left(y_{i}\right)=\mu_{i} ; \operatorname{Var}\left(y_{i}\right)=\sigma^{2}{ }_{y i}, \\
E(y)=\mu ; \operatorname{Var}(y)=\sigma^{2} .
\end{gathered}
$$

Thus equation (1) decomposes changes in individual yield into a component that is systematically related to area yield, through the term $\beta_{i}(y-\mu)$, and a random component, $e_{i}$, uncorrelated with area yield. The coefficient $\beta_{i}$ measures the sensitivity of individual yield to movements in area yield. If $\beta_{i}$ is greater (less) than one, changes in the area average yield result in larger (smaller) absolute changes in farm i's individual yield.

As noted above, under an area yield contract in which the coverage level $\phi_{i}$ is one, the farm receives a positive indemnity when its trigger yield, $y_{c i}$, exceeds the actual area yield; otherwise the indemnity, $n_{i}$, is zero; that is,

$$
n_{i}=\operatorname{Max}\left(y_{c i}-y ; 0\right),
$$

If the per acre premium, $r_{i}$, is fair, it is equal to the expected value of the indemnity, $E\left(n_{i}\right)$ and, as Miranda notes, each contract can be evaluated solely in terms of effects on the variance of net yield if producers are mean variance utility maximizers. ${ }^{11}$ This assumption is also adopted here. Net yield, $y_{i}^{\text {net }}$ is defined as:

$$
y_{i}^{n e t}=y_{i}+n_{i}-r_{i} \text {. }
$$

and its variance, which measures the farm's yield risk, is therefore

(8) $\operatorname{Var}\left(y_{i}^{n e r}\right)=\sigma^{2}{ }_{y i}+\sigma^{2}{ }_{n i}+2 \operatorname{Cov}\left(y_{i}, n_{i}\right)$

where $\sigma_{n i}^{2}$ denotes $\operatorname{Var}\left(n_{i}\right)$. The reduction in yield risk of the $i$ 'th farm, as measured by the change in the variance of net yield, is therefore:

$$
\begin{aligned}
D_{i} & =\operatorname{Var}\left(y_{i}\right)-\operatorname{Var}\left(y_{i}^{n e t}\right) \\
& =-\sigma^{2}{ }_{n i}-2 \operatorname{Cov}\left(y_{i}, n_{i}\right)
\end{aligned}
$$

If $e_{i}$ and $\mathrm{y}$ are uncorrelated, it follows that:

$$
\operatorname{Cov}\left(y_{i}, n_{i}\right)=\beta_{i} \operatorname{Cov}\left(y, n_{i}\right) \text {. }
$$

Miranda then introduces the concept of a critical beta, $\beta_{c}$, such that

$$
\beta_{c i}=-\sigma_{n}^{2} / 2 \cdot \operatorname{Cov}\left(y, n_{i}\right) .
$$

Note that $\beta_{c i}$ has a unique value for each trigger yield $y_{c i}=\alpha_{i} y$, and therefore is unique for each $\alpha_{i}$ because as $\alpha_{i}$ increases so does $y_{c i}$ and, therefore,

\footnotetext{
11 We abstract from any consideration of price risk in the analysis. Thus, following Miranda, yield risk is assumed to be the sole source of farm revenue variation.
} 
$n_{i}$. The reduction in yield risk can then be written as:

$$
D_{i}=\sigma_{n i}^{2}\left[\beta_{i} / \beta_{c i}-1\right]
$$

This expression is strictly positive as long as $\beta_{i}>$ $\beta_{c i}$. The maximum value for $\beta_{c}$ is 0.5 and, as Miranda shows, the weighted average of the $\beta_{i}$ 's is 1 (where the weight for each farm is its share of total area acreage). Thus most farms will enjoy reductions in yield variability and yield risk under an area yield program.

It can be shown that if $\beta_{c i}$ lies in the range $0 \leq$ $\beta_{c i} \leq 0.5$ then under weak regularity conditions $\beta_{c i}$ is monotonically increasing in $\alpha_{i}$ and that in the limit, as $\alpha_{i}$ approaches infinity, $\beta_{c i}=0.5$ (Miranda). In Miranda's example, the upper limit value for $\beta_{c i}$ is reached when $\alpha_{i}=1.25$ and in the sample presented below it is reached when $\alpha_{i}=$ 1.35. Interestingly, once the limit value for $\beta_{c}$ is reached, no farm can further reduce the variance of its net yields by choosing a higher value for $\alpha_{i}$. This occurs because, as is clear from equation (11), when $\beta_{c i}$ is 0.5 the ratio of the variance of indemnities to the covariance of indemnities and area yield is -1 ; that is, indemnities and area yield have become perfectly negatively correlated in the sense that a one unit increase in y reduces $n_{i}$ by one unit. An "almost ideal" insurance contract under which the farm only selects a value for $\alpha_{i}$ therefore contains an implicit upper bound for both $\alpha_{i}$ and the trigger yield.

Once a trigger yield, $y_{c i}$, has been selected through the choice of $\alpha_{i}$ the farmer may be able to further reduce the variance of net yields by opting to receive an indemnity that is larger or smaller than the "standard" indemnity, $n_{i}=y_{c i}-y$, when losses occur; that is, it may opt for a "coverage" level, $\phi_{i}$, that differs from 1 . Taking the choice of the trigger yield as given, when $\phi_{i}$ is a choice variable, the $i$ 'th farmer's net yield becomes:

$$
y_{i}^{\text {net }}=y_{i}+\phi_{i} n_{i}-\phi_{i} r_{i}
$$

Note that the premium associated with the receipt of $n_{i}$ is also multiplied by $\phi_{i}$ to insure that the contract remains actuarially fair. The variance reduction obtained from this form of area yield contract is:

$$
\begin{aligned}
D_{i} & =\operatorname{Var}\left(y_{i}\right)-\operatorname{Var}\left(y_{i}^{n e t}\right) \\
& =-\phi_{i}^{2} \sigma_{n i}^{2}-2 \phi_{i} \operatorname{Cov}\left(y_{i}, n_{i}\right) .
\end{aligned}
$$

Using equation (10), this expression can be rewritten as:

$$
D_{i}=\sigma^{2}{ }_{n i}\left[\phi_{i} \cdot \beta_{i} / \beta_{c i}-\phi_{i}^{2}\right] .
$$

Given that the choice of the trigger yield, and therefore of $\beta_{c i}$ and $\sigma_{n i}{ }^{2}$, has already been made, the locally optimal value for $\phi_{i}$ that minimizes $D_{i}$ is simply:

$$
\phi_{i}^{*}=\beta_{i} / 2 \beta_{c i} \text {. }
$$

Equation (16) suggests that most farms will choose a coverage level in excess of one. The maximum value the farm can choose for $\beta_{c}$ through its choice of a trigger yield is 0.5 and, as noted above, the weighted average value of the $\beta_{i}$ 's is one. Thus even if all farms selected the maximum risk reducing trigger yield, about half of the farms would opt for $\phi_{i}$ 's in excess of one and, given that at least some farms will choose trigger yields for which $\beta_{c i}$ $<0.5$, even if their $\beta_{i}$ 's are less than one their optimal coverage levels may be larger than 1 . In some cases, where $\beta_{c i}$ is small and $\beta_{i}$ is large, the optimal coverage level may be very large. ${ }^{12}$

\section{A Comparison of Alternative Area Yield Contracts}

The above theoretical analysis suggests that a globally optimal area yield contract (that maximizes the i'th farm's risk reduction) requires that the farm be permitted to choose values for both $\alpha_{i}$ and $\phi_{i}$ that may be greater than one. In other words, many farms will find it optimal to "over insure" against area yield. The current FCIC area yield contract constrains the farm's choice of the trigger yield to be no more than 90 percent of average area yield $\left(\alpha_{i} \leq 0.9\right)$ and the coverage level to be less than 150 percent $\left(\phi_{i} \leq 1.5\right)$. One important question is how costly are the constraints of the FCIC pilot area yield program to farmers in terms of lost opportunities for risk reduction. A second is whether a simpler contract exists that would provide levels of risk reductions that are close to those available under the "ideal" contract for most farms.

To address these issues empirically, data were obtained on individual annual yields for 123 separately insured dryland wheat operations in Chouteau County, Montana, over the ten year period 1981-90 from the FCIC. ${ }^{13,14}$ The yield data for

\footnotetext{
${ }^{12}$ In Miranda's sample, the maximum optimal value for $\phi_{i}$ was 4.77 (a coverage level of 477 percent), and coverage levels in excess of 200 percent were quite common.

${ }^{13}$ Data on yields were available from FCIC only for farms that had insured their crops on at least one occasion during the $1980 \mathrm{~s}$. The sample used here, therefore, is not a random sample. However, since 1983, in any given year about 85 percent of all dryland wheat acreage has been insured in that region of Montana. Thus, the bias introduced by examining yields only for farms that have purchased MPCI may not be too serious.
} 


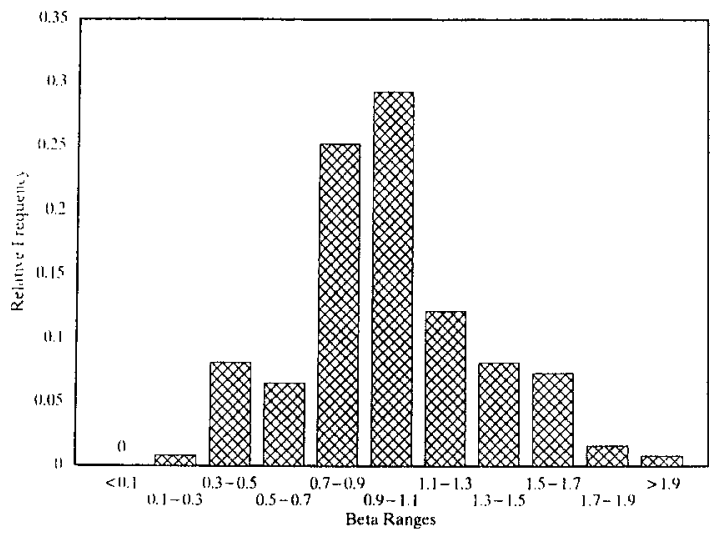

Figure 1. Frequency Distribution of Individual Producer Betas

each farm were examined for trend over the 10 year period but no evidence of any trend was found. ${ }^{15}$ Individual yields were weighted by each operation's share of total acreage planted by the 123 operations to estimate the annual average area yield, $y$, for each year. This series also exhibited no distinguishable time trend and thus a simple average of the annual area yields over the sample period was used as an estimate of the expected value for the area yield, $\mu$.

Estimates of the $\beta_{i}$ 's were obtained for each farm in the sample. A histogram of their distribution is presented in Figure 1. The range of values for the $\beta_{i}$ 's is $0.24-1.93$, only 11 farms in the sample have $\beta_{i}$ 's that are less than 0.5 and no farm in the sample is unable to obtain some risk reduction from any of the area yield contracts examined below. About 56 percent of farms have $\beta_{i}$ 's that are less than one, indicating that smaller farms in the sample tend to have smaller $\beta_{i}$ 's (because the acreage weighted average of the $\beta_{i}$ 's is 1 ).

Estimates of reductions in yield variance available under each of the three area yield contracts described in Table 1 were obtained as follows. First, estimates of the annual values for $n_{i}, \sigma_{n i}{ }^{2}$ and $\beta_{c i}$ were computed for all values of $\alpha_{i}$ in the range $0-3$ where $\alpha_{i}$ was initially set equal to 0 and increased in increments of 0.05 . The limit value for $\beta_{c i}$ was obtained for $\alpha_{i}$ equal to 1.35. Thus no farm in this sample could obtain any additional risk re-

\footnotetext{
${ }^{14}$ In this sample, in several cases, the same producer farms more than one of the operations but, as each operation is subject to a separate insurance contract under the MPCI program, operations are not aggregated by producers in the analysis presented here.

${ }^{15}$ Inspection of plots provided no evidence of any persistent trends in individual yields and when yields were linearly regressed on time, not one of the 123 estimated coefficients on time was significantly different from zero.
}

duction from contracts in which $\alpha_{i}>1.35$. Next, for each farm, equation (12) was used to calculate the risk reduction obtained from a contract in which $\phi_{i}$ was set equal to one for all values of $\alpha$ over the range of $0-1.35$ and the trigger yield (and corresponding values for $\beta_{c}$ and $\sigma_{n}^{2}$ ) that maximized risk reduction under such a contract was identified. This procedure identified the optimal "almost ideal" contract for each farm in the sample. Next, to identify the "ideal" contract, equation (16) was used to identify the optimal value for $\phi_{i}$, given that $\alpha_{i}$ was set equal to its optimal value under the "almost ideal" contract. ${ }^{16}$ Equation (15) was then used to compute the risk reduction obtained under the farm's optimal "ideal" contract.

Optimal contracts under the FCIC pilot area yield program were identified as follows. A farm whose "ideal" contract consisted of an $\alpha_{i}<0.9$ and a $\phi_{i}<1.5$ still had access to such a contract under the pilot program. Farms with an optimal $\alpha_{i}$ $<0.9$ and an optimal $\phi_{i}>1.5$ under the "ideal" contract were constrained to set $\phi_{i}$ equal to 1.5. Farms with an optimal $\alpha_{i}>0.9$ were constrained to set $\alpha_{i}$ equal to 0.9 and to select the optimal value for $\phi_{i}$ given that $\alpha_{i}=0.9$, unless that value for $\phi_{i}$ exceeded 1.5. In that case, both $\alpha_{i}$ and $\phi_{i}$ were set equal to their limit values under the pilot program. Risk reductions obtained under the optimal FCIC pilot program were also computed using equation (15). Finally, to facilitate comparisons of the risk reductions achieved under each of the three contracts, the absolute value of the decrease in variance of net yields obtained under each area yield insurance contract, $D_{i}$, was divided by the variance of individual yields (that is, the variance of net yields in the absence of any insurance contract).

Table 2 presents information on the average proportional decrease in risk (that is, in the variance of net yields) under each of the three area yield contracts. The estimates of risk reduction are presented in absolute values and thus larger percentage changes imply larger reductions in risk. The results presented in Table 2 are quite dramatic. The current FCIC pilot program, AYC1, provides the average farm in the sample with a 52.5 percent reduction in individual net yield variance. However, the "almost ideal" contract, AYC2, permits the average farm to reduce the variance of it net yields by 63 percent, a 19.9 percent larger reduction in risk than that provided by the FCIC pilot

\footnotetext{
16 To check that this procedure resulted in a globally-optimal contract for the $i$ 'th farm, a search was carried out over all feasible values of $\alpha$ and $\phi$ for a sub-sample of five individual farms. In each case, the comprehensive search identified the same contract as the two-step procedure.
} 
Table 2. Proportional Decreases in Average Farm Level Net Yield Variances Under Three Alternative Area Yield Insurance Contracts

\begin{tabular}{|c|c|c|c|c|}
\hline & $\begin{array}{l}\text { Number } \\
\text { of Farms }\end{array}$ & AYC1 & AYC2 & AYC3 \\
\hline & \multicolumn{4}{|c|}{ Percent change } \\
\hline All farms & 123 & 52.54 & 63.00 & 65.62 \\
\hline
\end{tabular}

contract. The "ideal" contract results in risk reduction of 65.6 percent for the average farm, an improvement of only 4 percent relative to the "almost ideal" contract. The "almost ideal" contract, which is simpler than both the FCIC pilot contract and the "ideal" contract, provides substantially more risk reduction than the FCIC pilot contract and almost as much risk reduction as the "ideal" contract.

Information on the average characteristics of the optimal area yield contracts purchased by farmers are presented in Table 3 . Under AYC1, the FCIC pilot contract, the average value for the $\alpha_{i}$ 's is 0.876 , very close to its limit value of 0.9 . Thus most farms in the sample will choose the maximum trigger yield, $y_{c}$, under this contract. In contrast, under the pilot program, the average farm selects a coverage level, $\phi_{i}$, of 1.285 that is almost 14 percent lower than the limit value of 1.5 .

The "almost ideal" program, AYC2, allows farms more flexibility in their choice of trigger yield but constrains them to select a $\phi_{i}$ of 1 . Under this contract, the average optimal trigger yield increases by over 42 percentage points (the average value of $\alpha_{i}$ increases from 0.876 to 1.246). However, the average farm in the sample also forced to reduce its optimal coverage level (the average value for $\phi_{i}$ falls from 1.285 to 1 ). These results suggest that restrictions on the choice of the trigger yield have much larger adverse effects on the ability of farms to reduce risk under area yield contracts than do restrictions on coverage levels.

These findings are confirmed by a comparison

Table 3. Average and Maximum Trigger Levels and Coverage Levels Selected Under Three Alternative Area Yield Insurance Contracts

\begin{tabular}{|c|c|c|c|c|c|c|}
\hline \multirow{2}{*}{$\begin{array}{l}\text { Average } \\
\text { Values }\end{array}$} & \multicolumn{2}{|c|}{ AYCl } & \multicolumn{2}{|c|}{ AYC2 } & \multicolumn{2}{|c|}{ AYC3 } \\
\hline & $\alpha_{i}$ & $\phi_{i}$ & $\alpha_{i}$ & $\phi_{i}$ & $\alpha_{i}$ & $\phi_{i}$ \\
\hline All farms & .876 & 1.285 & 1.246 & 1.00 & 1.246 & 1.074 \\
\hline \multicolumn{7}{|c|}{ Maximum Values } \\
\hline All farms & .900 & 1.500 & 1.350 & 1.00 & 1.350 & 1.926 \\
\hline
\end{tabular}

of the "almost ideal" contract and the "ideal" contract. Farms in the sample do not change their trigger yields under the ideal area yield contract from those selected under the almost ideal area yield contract but do increase their coverage levels by 7.4 percentage points (the average value for $\phi_{i}$ increases from 1 to 1.074). As noted above, as a result they obtain levels of risk reduction that are about 4 percent higher.

The findings presented in Table 3 indicate that farms purchase different levels of area yield insurance coverage under each of the three contracts. Under each contract, expected indemnities will be different and, therefore, actuarially fair premiums will be different. Table 5 presents the average actuarially fair premiums (in bushels per insured acre) that would be charged if each farm chose its optimal insurance plan under each contract. Under the FCIC pilot contract, AYC1, the average per acre premium is 4.34 bushels; the per acre premium is more than twice as high, 11.05 bushels, under the "almost ideal" contract, AYC2, and under the "ideal" contract, AYC3, rises to 19.18, almost double the premium for AYC2 and over four times the premium for AYC1.

Table 5 provides interesting insights about why the FCIC pilot contract might have been chosen. First, if the government is committed to subsidizing a fixed percentage of expected losses, and therefore premiums, from area yield insurance contracts (as is implied for MPCI under the terms of the 1980 Federal Crop Insurance Act), its total fiscal outlays will be much smaller under the FCIC pilot contract than under either the "almost ideal" contract or, especially, the "ideal" contract. Second, even though each of the contracts is actuarially fair, farms may simply be reluctant to pay relatively high per acre premiums for an individual contract. If wheat output is valued at $\$ 2.80$ per acre (as is the case under the 1993 FCIC pilot contract) then under the pilot contract, average per acre premiums would be $\$ 12.15$, under the "almost ideal" contract they would be $\$ 30.94$, and under the "ideal" contract they would be $\$ 53.70$. Average per acre yields in the sample were about 33 bushels per acre during the 1980s. Thus the optimal "ideal" contract would require farmers to pay about two thirds of expected gross revenues in insurance payments, though they would also receive indemnities even in years when area yields are considerably above average. This problem is less severe under the "almost ideal" contract but is still not a trivial concern.

A relevant issue with any area yield contract is how it compares to current and alternative individual yield insurance contracts. Table 4 shows aver- 
Table 4. Proportional Decreases in Average Farm Level Net Yield Variances Under Two Area Yield Insurance Contracts and Two Representative Individual Yield Insurance Contracts (Percent Reduction in Net Yield Variance)

\begin{tabular}{cccccc} 
& \multicolumn{2}{c}{ Area Yield Insurance } & \multicolumn{2}{c}{$\begin{array}{c}\text { Individual Yield } \\
\text { Insurance }\end{array}$} \\
\cline { 2 - 5 } & AYC1 & AYC2 & IYC1 & IYC2 \\
\cline { 2 - 3 } \cline { 4 - 6 } All farms & 52.54 & \multicolumn{2}{c}{$\begin{array}{c}\text { Percent reduction } \\
63.00\end{array}$} & 46.55 & 64.31 \\
\hline
\end{tabular}

age reductions in the variance of net yields under the three area yield contracts, the 75 percent individual yield contract that is currently available under the MPCI program (IYC1) and the 90 percent individual yield contract (IYC2). The 75 percent individual yield contract provides risk reductions (on average, a 46.5 percent decrease in net yield variance) that are roughly equivalent to those available under the FCIC pilot program (on average, a 52.5 percent decrease in net yield variance), which suggests that the FCIC pilot program may have been constructed with this goal in mind. The 90 percent individual yield contract provides reductions in risk that are roughly equivalent to those available under the "almost ideal" area yield contract.

Average actuarially fair premiums for all five contracts are presented in Table 5. The average per acre premium for IYC1 (2.63 bushels) is about 40 percent lower than that for AYC1 (4.34 bushels) although both contracts provide farms similar reductions in yield risk. The average per acre premium for IYC2 ( 4.17 bushels) is over 60 percent lower than that for AYC2 (11.05 bushels) although, again, both contracts offer farms similar reductions in yield risk. In other words, in the absence of adverse selection and moral hazard, individual yield contracts provide farms with similar

Table 5. Average Per Acre Premiums Under Three Area Yield Insurance Contracts and Two Individual Yield Insurance Contracts

\begin{tabular}{|c|c|c|c|c|c|}
\hline & \multicolumn{3}{|c|}{ Area Yield Insurance } & \multicolumn{2}{|c|}{$\begin{array}{l}\text { Individual Yield } \\
\text { Insurance }\end{array}$} \\
\hline & AYC1 & AYC2 & $\mathrm{AYC} 3$ & IYC1 & IYC2 \\
\hline & \multicolumn{5}{|c|}{ Bushels Per Acre } \\
\hline All farms & 4.34 & 11.05 & 19.18 & 2.63 & 4.17 \\
\hline
\end{tabular}

yield risk protection but at much lower premiums. Thus, even if there were no potential for gains from asymmetric information under individual yield contracts many farms would still prefer them to area yield contracts because lower premiums would place less stress on the farm's cash flow.

\section{Conclusions and Policy Implications}

This paper has examined the effects of three alternative area yield crop insurance contracts on net yield variance among a sample of 123 dryland wheat operations. We have shown that the current area yield pilot contract offered by the FCIC, under which the farm has constrained choices both with respect to its trigger yield and coverage level, allows almost all farms to reduce yield variance and yield risk quite significantly. However, a simpler "almost ideal" area yield contract, that provides the farm only with an unrestricted choice of trigger yield and a single coverage level of 100 percent, allows all farms in the sample to reduce yield variability by much larger amounts but at higher premiums. An "ideal" contract, under which the choices of both the trigger yield and coverage level are unconstrained, allows farms to achieve only small additional yield risk reductions relative to the "almost ideal" contract, but requires most farms to pay substantially higher premiums.

The above findings suggest that, because farmers appear to benefit substantially from increased opportunities to reduce yield risk under an actuarially equivalent "almost ideal" area yield contract, the FCIC should consider offering such a contract, at least on an experimental basis. The fact that the "almost ideal" contract is simpler is also in its favor. A major concern among policy makers and crop insurance administrators is how to increase participation in insurance based disaster mitigation programs. In that context, a simpler area yield contract that is also more advantageous for most farms may be a better deal for all of the parties involved.

The results presented in this paper also indicate that individual yield insurance contracts provide about the same degree of yield risk reduction at lower premium rates. Thus, even in the absence of opportunities for moral hazard and adverse selection, in general, farmers will prefer an individual yield program to an area yield program. Therefore, if individual yield contracts could be "made" to work efficiently - that is, moral hazard and adverse selection problems could be overcome-they would still be preferred. Work by Raviv and others 
suggests that in general, multi-period insurance agreements in which premiums are tied to losses (as with auto-insurance), go a long way to solving moral hazard and adverse selection problems. Policy makers might therefore also consider experimenting with such contracts, at least on a pilot basis, in addition to examining an expanded array of area yield contracts.

\section{References}

Arnott, R.J. and J.E. Stiglitz. "The Basic Analytics of Moral Hazard." Scandinavian Journal of Economics. (1988): 383-413.

Bardsley, P., A. Abey, and S. Davenport. "The Economics of Insuring Crops Against Drought." The Australian Journal of Agricultural Economics. 28(1984):1-14.

Borch, K. The Economics of Uncertainty. Princeton: Princeton University Press, 1968.

Carriker, G.L., J.R. Williams, G.A. Barnaby, and J.R. Black. "Yield and Income Risk Reduction under Alternative Crop Insurance and Disaster Assistance Designs." Western Journal of Agricultural Economics. 16(1991):238-50.

Chambers, R.G. "Insurability and Moral Hazard in Agricultural Insurance Markets." American Journal of Agricultural Economics. 71(1989):604-16.

Coble, K.H., T.O. Knight, R.D. Pope, and J.R. Williams. "An Empirical Test for Moral Hazard and Adverse Selection in Multiple Peril Crop Insurance." Paper presented at the AAEA Summer Meetings, Orlando, Florida, August 1993.

Fraser, R.W. "An Analysis of Willingness-To-Pay for Crop Insurance." Australian Journal of Agricultural Economics. (April 1992):83-95.

Gardner, B.L. and R.A. Kramer. "Experience with Crop Insurance Programs in the United States." in P. Hazell, C. Pomareda, and A. Valdes (eds), Crop Insurance for Agricultural Development, Johns Hopkins University Press, Baltimore.

Goodwin, B.K. "An Empirical Analysis of the Demand for Multiple Peril Crop Insurance." American Journal of Agricultural Economics. 75(1993):425-34.

Goodwin, B.K. and T.L. Kastens. "Adverse Selection, Disas- ter Relief, and the Demand for Multiple Peril Crop Insurance." A Research Report Prepared for the Federal Crop Insurance Corporation (Project No. 92-EXCA-3-0209). Kansas State University, 1993.

Grossman, S.J. and O.D. Hart. "An Analysis of the PrincipalAgent Problem." Econometrica. 51(1983):7-45.

Halcrow, H.G. "Actuarial Structures for Crop Insurance." Journal of Farm Economics, 31(1949):418-43.

Horowitz, J.K. and E. Lichtenberg. "Insurance, Moral Hazard, and Chemical Use in Agriculture." American Journal of Agricultural Economics. Forthcoming, 1993.

Just, R.E. and L. Calvin. "Adverse Selection in U.S. Crop Insurance: The Relationship of Farm Characteristics to Premiums." Unpublished working paper, University of Maryland, College Park, Maryland. 1993.

Just, R.E. and L. Calvin. "Moral Hazard in U.S. Crop Insurance: An Empirical Investigation."' Unpublished working paper, University of Maryland, College Park, Maryland. 1993.

Miranda, M.J. "Area-Yield Crop Insurance Reconsidered." American Journal of Agricultural Economics. (1991):23342.

Nelson, C.H. and E.T. Loehman. "Further Toward a Theory of Agricultural Insurance." American Journal of Agricultural Economics. 69(1987):523-31.

Patrick, G.F. "Mallee Wheat Farmers' Demand for Crop and Rainfall Insurance." Australian Journal of Agricultural Economics. 32(1988):37-49.

Quiggin, J. "A Note on the Viability of Rainfall Insurance." Australian Journal of Agricultural Economics. 30(1986): 63-69.

Raviv, A. "The Design of An Optimal Insurance Policy." American Economic Review. 69(1979):84-96.

Skees, J.R. and M.R. Reed. "Rate Making and Farm-Level Crop Insurance: Implications for Adverse Selection." American Journal of Agricultural Economics. 68(1986): 653-59.

Williams, J.R., G.L. Carriker, G.A. Barnaby, and J.K. Harper. "Crop Insurance and Disaster Assistance Designs for Wheat and Grain Sorghum." American Journal of Agricultural Economics. 75(1993):435-47.

Zering, K.D., C.O. McCorble, Jr., and C.V. Moon. "The Utility of Multiple Peril Crop Insurance for Irrigated, Multiple-Crop Agriculture." Western Journal of Agricultural Economics. 12(1987):50-59. 